\title{
Prevalence of Modifiable Risk Factors for Sudden Infant Death Syndrome in British Forces Germany
}

\section{Lt Col SAStJ Miller}

MSc, MFPHM, MRCGP, RAMC

Parkes Professor

Royal Army Medical College, Millbank, London SW1P 4R.I

\author{
Miss MM Morrison \\ SSAFA Senior Nurse
}

MRS Sennelager, BFPO 16

SUMMARY: A questionnaire survey was conducted amongst parents in the military community in British Forces Germany to investigate the prevalence of known and suspected risk factors for Sudden Infant Death Syndrome. Over a thousand questionnaires were returned (response rate $58 \%$ ) and these showed that the prevalence of babi being placed in the prone position to sleep is now extremely low and the use of room thermometers to help contr?ु్ ambient temperature is widespread. However $29 \%$ of the mothers had smoked in pregnancy and $44 \%$ if households with a new-born baby had at least one parent who smoked. Additional health promotion activity aim\& at reducing the prevalence of smoking in pregnancy and amongst the parents of new-born babies is recommende兽

\section{Introduction}

Since every cot death is a human tragedy, with devastating consequences for the entire family, its prevention has attracted a large amount of medical research. Those cot deaths which remain unexplained after detailed post mortem investigation are more accurately described as deaths due to Sudden Infant Death Syndrome or SIDS. Unfortunately this syndrome has proved extremely difficult to explain and although many theories have been put forward the precise pathophysiology remains unknown (1).

It has therefore been necessary to place considerable reliance on epidemiological research. This type of research has identified a number of risk factors for SIDS but it has not been easy to determine the relative importance of each one separately because they are often inter-related. Some of the risk factors such as twin pregnancy, low birth weight, prematurity, low maternal age, winter season, and age between 6 and 18 weeks, are largely unavoidable but some of these have been useful in identifying families at increased risk of SIDS so that extra advice and support can be offered (2). Other risk factors have been identified which are potentially preventable such as the prone sleeping position, excessive temperature, and parental smoking $(3,4,5)$. Although these risk factors do not directly cause SIDS they appear to be associated to such an extent that when they are deliberately avoided the incidence falls.

Since the 1960 s there have been several retrospective studies which have suggested that SIDS was more likely to occur when infants slept in the prone position. The evidence for this theory was considerably strengthened when both New Zealand and the Avon health district in England reported fewer deaths after their parental education programmes were introduced (6). Althey avoiding the prone position was not the only advice ofven to parents it seems to have been the only change they made to their parenting habits and is there $\overrightarrow{0}^{+}$व thought to have been mainly responsible for the refent improvement (7). We still do not know exactly hतु helps.

Evidence has been accumulating that overheating a part in some cases of SIDS (4). It is not a cause of as such but seems to be a contributory factor, particula in the presence of fever, and is therefore acknowledged increase the risk (8). As a result of this evidence SSAF midwives now issue the parents of all new-born babies $\overline{\hat{Q}}$ n British Forces Germany with a room thermometer to he them to maintain the ambient temperature at appropria levels. There is also good evidence that cigarette smokifig is associated with an increased risk but it is not yet cle whether maternal smoking in pregnancy or passi smoking in infancy is the more important. Both appear be significant risk factors and the risk is directly related $\mathscr{\Phi}_{0}$ the number of cigarettes smoked (9).

The growing evidence that these three factors wige implicated in SIDS was considered sufficient for the Department of Health to launch its campaign $\Phi_{n}$ November 1991 advising parents that the risk would Be reduced if a baby was placed on its side or back rathor than on its front unless there are medical reasons doing so, if it was not exposed to cigarette smoke durimg pregnancy and after birth, and if overheating was avoidfor (9). It is now considered safest if babies are laid on ther backs rather than on their sides and if the side position chosen the lower arm should be well in front of the bogk so that the infant does not roll onto the front. 
There are other factors which some researchers believe to be important in the prevention of SIDS. The most important of these are breastfeeding and sleeping in the same room as parents but the evidence is inconclusive. The Chief Medical Officer's Expert Group decided that breast feeding is not definitely associated with any reduction in the risk although it is considered beneficial for other reasons (9). There is also no direct evidence that the risk is reduced if the baby sleeps in the same room as the parents although the low incidence of SIDS in certain ethnic communities where babies remain in close proximity to the parents suggests that this should be explored further (10).

Cot death prevention has always been an important issue for the military community because of the high birth rate, the number of young parents, the lack of extended family support, and the relative turbulence and isolation which some military families encounter. Although the infant mortality rates for British Forces Germany have, since the early $1980 \mathrm{~s}$, been satisfactory in comparison with the rates for all social classes in the civilian population of England and Wales (Fig 1) the SIDS rates have tended to be higher until recently (Fig 2 and Table 1). This is not an entirely satisfactory comparison because it does not allow for differences between the military and civilian populations. However until more work is done on the demographic characteristics of the military community such crude comparisons are the only ones that can be made.
Because of the importance of cot death prevention the military community it was considered necessary find out the prevalence of potentially avoidable ris factors and thereby enable health promotion to be directed as effectively as possible. A survey was therefore carried out amongst the families of all the babies born in Britis Forces Germany during one calendar year.

\section{Method}

Health visitors were asked to complete a questionnaie at first contact with the parents of all babies born British Forces Germany between 1 April 1994 and 39 March 1995. This provided general epidemiologic information and the prevalence of potentially preventable risk factors for SIDS. It was not possible to gather direc information about the risk of infants overheating so thम्ट use of room thermometers was investigated instead as index of parental awareness of the danger. The prevalen⿳亠丷厂 of not breast feeding and of not sharing the same room parents was also measured although the evidence that these are independently associated with cot death is nop conclusive.

Confidentiality was preserved by not recording an names on the questionnaires but health visitors were asked to include the British Forces Post Office numbef 50 that areas could be identified in the analysis. Whee questionnaire was based, with permission, on the one fic in the New Zealand Cot Death Prevention Programme It was hoped that its completion would, in addition

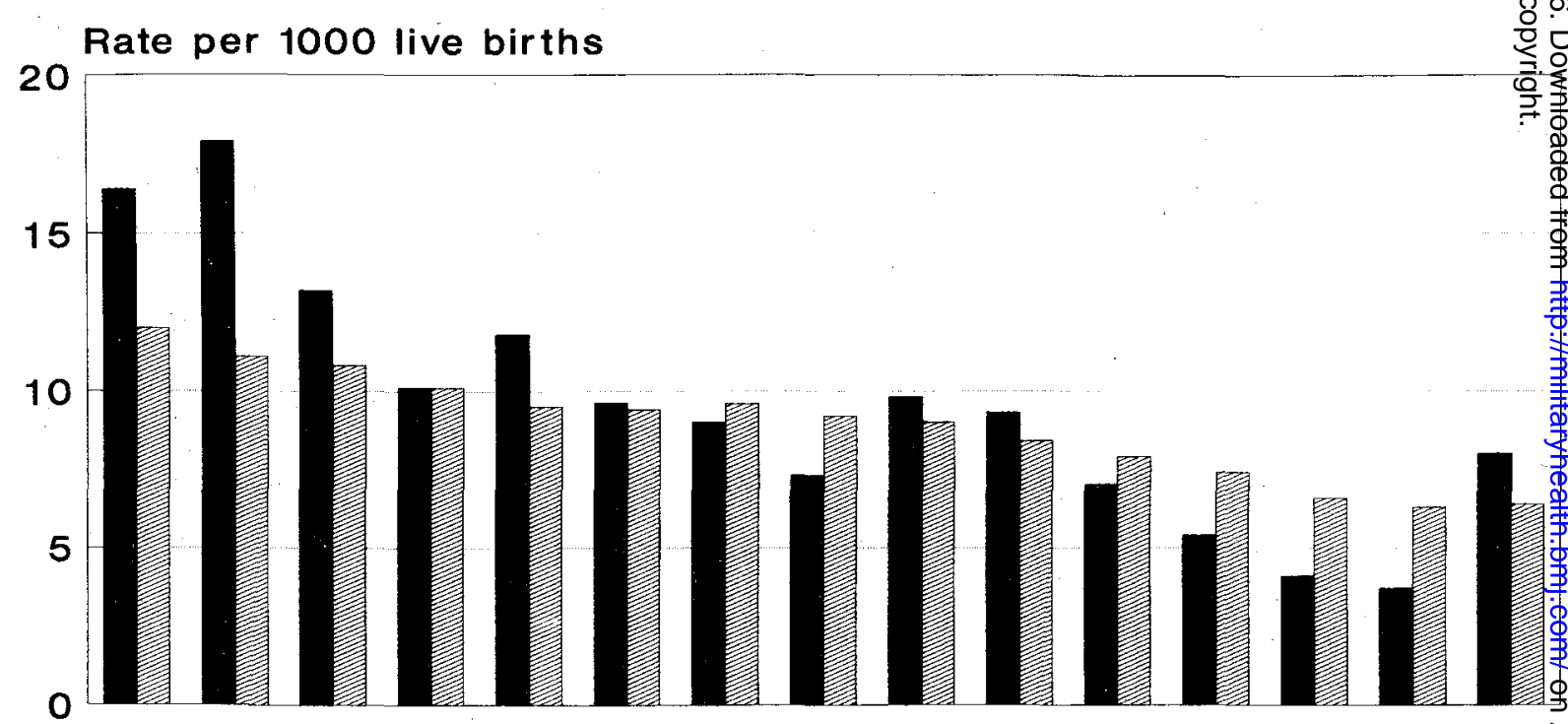

198019811982198319841985198619871988198919901991199219931994

Year

Source for E\&W: OPCS

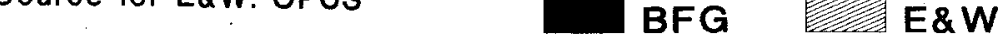

Fig 1. Infant mortality rates for British Forces Germany (1980-1994) and for England and Wales (all social classes) 

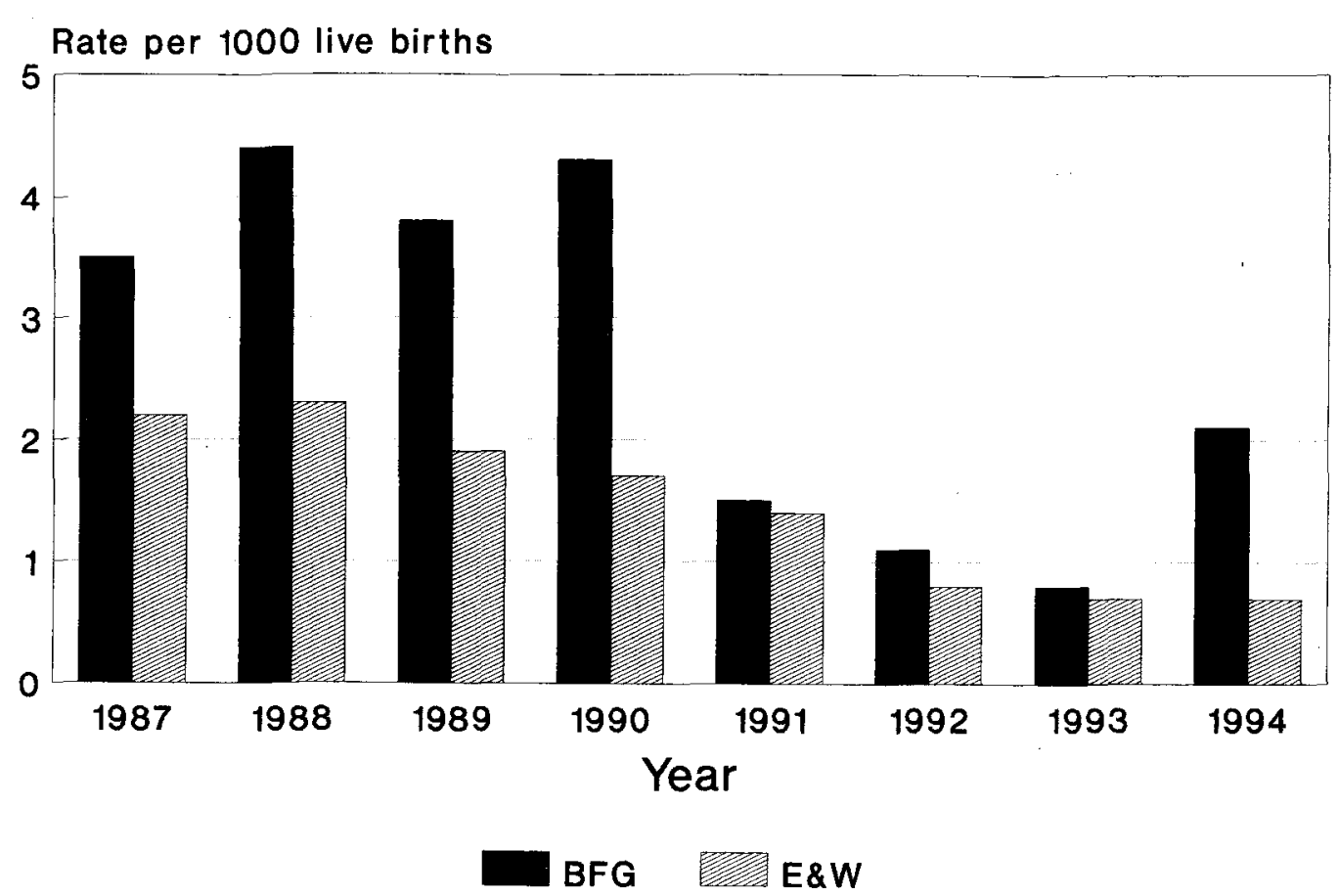

Source for E\&W: OPCS

Fig 2. SIDS rates for British Forces Germany (1987-1994) and for England and Wales (all social classes)

Table 1

Comparison of SIDS rates for British Forces Germany and for all social classes in England and Wales (1987-1994)

\begin{tabular}{|c|c|c|c|}
\hline Year & BFG & England \& Wales & Rate ratio, $95 \% \mathrm{Cl}$ and $\mathrm{p}$ values \\
\hline 1987 & 3.6 per 1000 & 2.2 per 1000 & $\begin{array}{l}1.59(0.92 \text { to } 2.70) \\
p=0.1\end{array}$ \\
\hline 1988 & 4.4 per 1000 & 2.3 per 1000 & $\begin{array}{l}1.93(1.19 \text { to } 3.09) \\
p=0.006\end{array}$ \\
\hline 1989 & 3.8 per 1000 & 1.9 per 1000 & $\begin{array}{l}1.98(1.10 \text { to } 3.50) \\
\mathrm{p}=0.02\end{array}$ \\
\hline 1990 & 4.0 per 1000 & 1.7 per 1000 & $\begin{array}{l}2.36(1.37 \text { to } 4.03) \\
p=0.001\end{array}$ \\
\hline 1991 & 1.2 per 1000 & 1.4 per 1000 & $\begin{array}{l}0.83(0.26 \text { to } 2.28) \\
\mathrm{p}=0.7\end{array}$ \\
\hline 1992 & 1.1 per 1000 & 0.8 per 1000 & $\begin{array}{l}1.42(0.45 \text { to } 3.92) \\
\mathrm{p}=0.69\end{array}$ \\
\hline 1993 & 0.8 per 1000 & 0.68 per 1000 & $\begin{array}{l}1.21(0.3 \text { to } 4.84) \\
p=0.9\end{array}$ \\
\hline 1994 & 2.1 per 1000 & 0.68 per 1000 & $\begin{array}{l}3.12(0.99 \text { to } 8.63) \\
p=0.05\end{array}$ \\
\hline
\end{tabular}


gathering necessary information, provide health visitors with the opportunity to advise parents about the Department of Health recommendations for reducing the risk.

The ethical implications of this research were considered at length by the research group which carried out the original study in New Zealand (11). While it was recognised that there was a possibility of increasing anxiety in the parents of some infants it was felt that the information was too important to be kept from the community at large. Informing parents was also considered likely to reduce anxiety about cot death in many cases since parents could then reduce the risk to their infants by modifying simple infant care practices.

\section{Results}

The total number of questionnaires completed was 1,014 and, since 1,760 babies were born in British Forces Germany during the study period, the response rate was $58 \%$. The average number of days after delivery on which the questionnaires were completed was 14 .

Figure 3 gives the pattern of the age distribution of the mothers in the study group compared with that for all social classes in the civilian population of England and Wales (12). The maternal age distribution within British Forces Germany was found to be significantly younger $(\mathrm{p}<0.001)$.

Only 10 mothers ( $1 \%$ of mothers in the study group) placed their babies in the prone position to sleep and not one of these was a first time parent. Ninety five percent of parents had received a room thermometer from the SSAFA midwife and $93 \%$ claimed to be using them.

Twenty nine percent of mothers in British Force Germany admitted to smoking in pregnancy. Postnata maternal smoking was slightly less prevalent at $26 \%$ : while fathers of new-born babies smoked in $34 \%$ of case This represented at least one parent in $44 \%$ of households with a new-born baby. Figure 4 shows a comparison o the smoking habits of the parents and Figure 5 showis maternal smoking by age. The prevalence of smoking wad significantly higher amongst younger mothers $(\mathrm{p}=0.002)$.

Fifty one percent were breast feeding to some degree at the time of first contact with the health visitor. OldeP mothers were significantly more likely to breastfeed $\overrightarrow{\mathrm{d}}$ $(\mathrm{p}<0.0001)$. Eighty six percent of parents reported tha their infants always slept in the same room as they dich $4 \%$ sometimes, and the remaining $10 \%$ never.

\section{Discussion}

Because the maternal age distribution within Britis Forces Germany was found to be significantly youngeङ than that of the civilian population of England and Wales it is necessary to be cautious when using the latter a yardstick for the military community. Furthermore $\vec{D} \vec{q}$ account has been taken of social class differences betwe the two populations as this was beyond the scope of $\frac{d h}{6}$

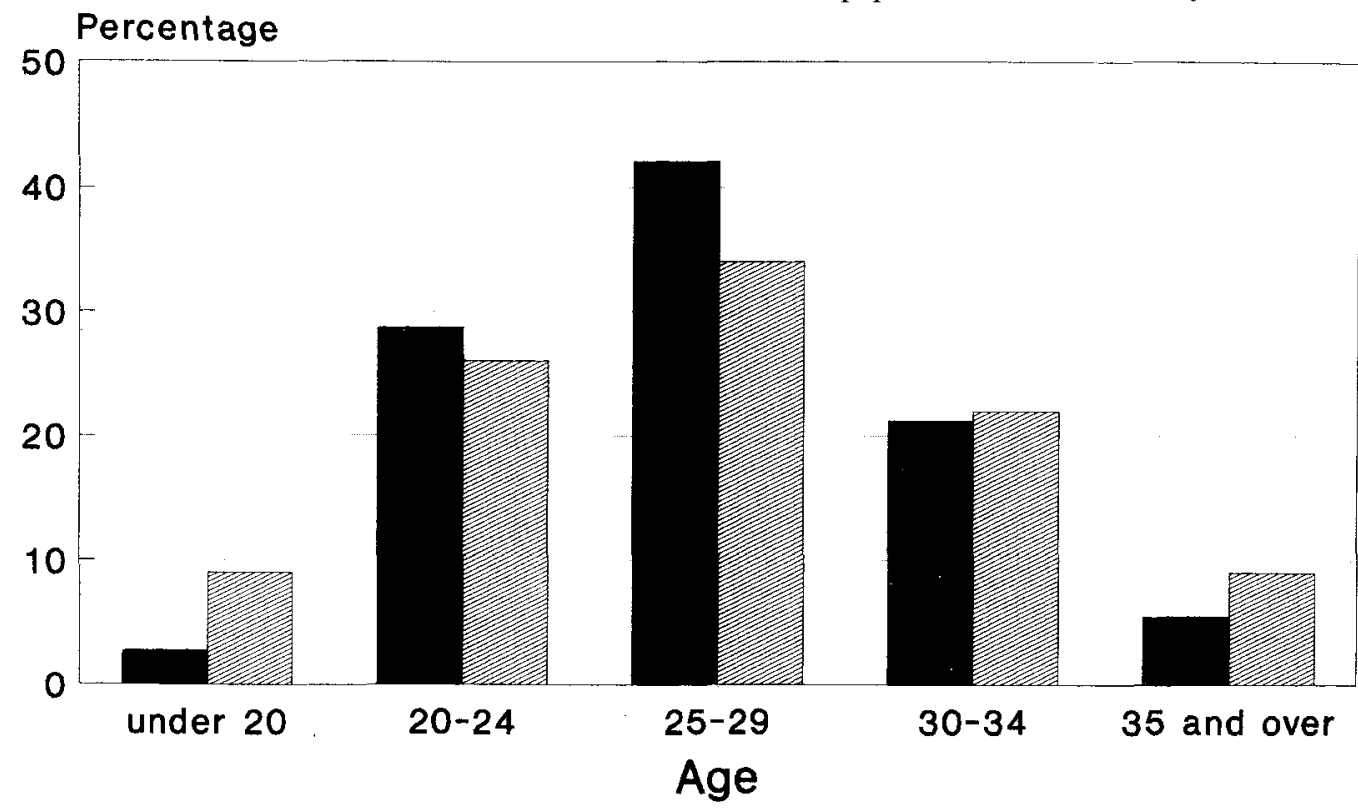

Source for E\&W: OPCS Birth Stats 1992.

$E \& W$

Fig 3. Comparison of maternal age distribution in British Forces Germany with England and Wales (all social classes) 


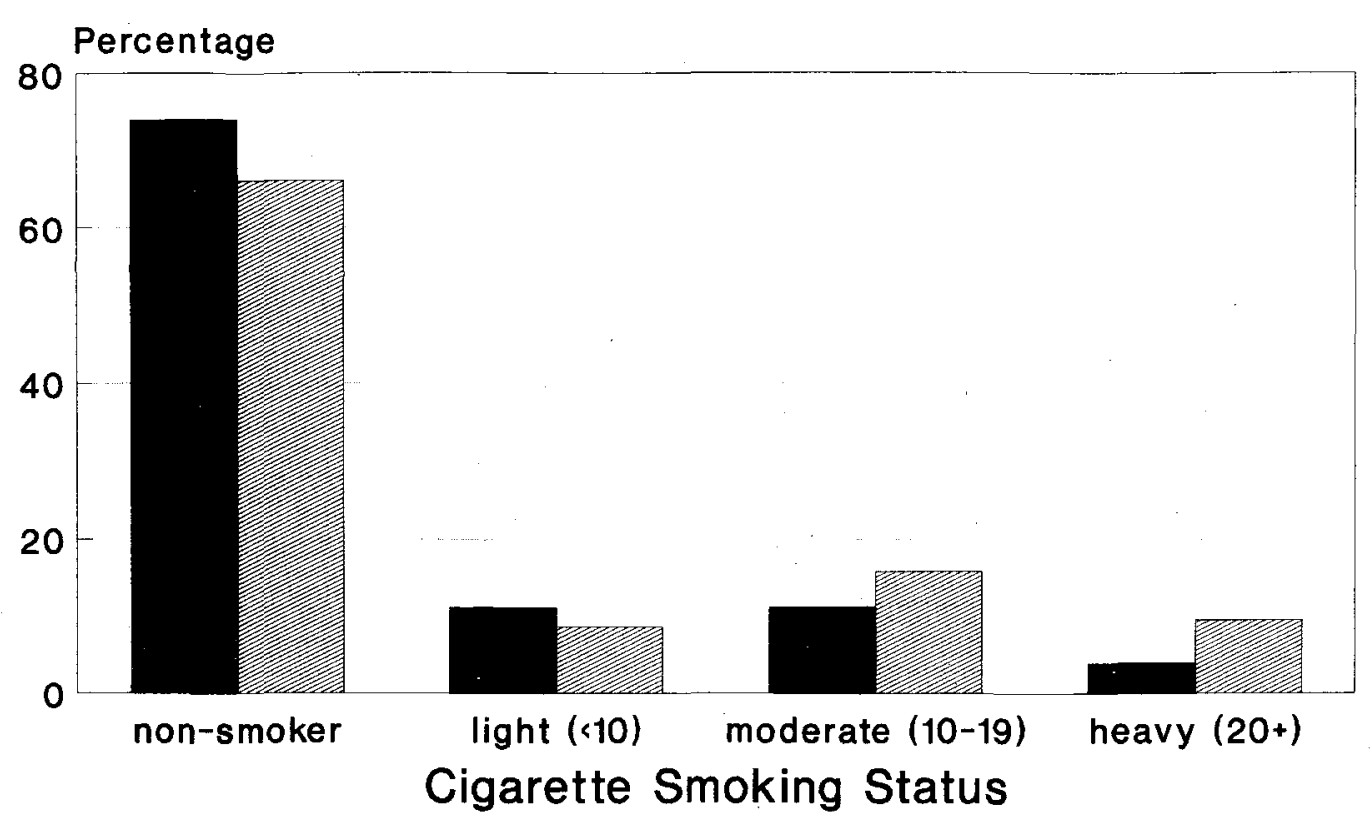

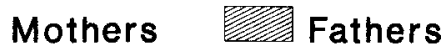

$\mathrm{N}=1002$ for mothers and 995 for fathers

Fig 4. Smoking habits of parents in British Forces Germany

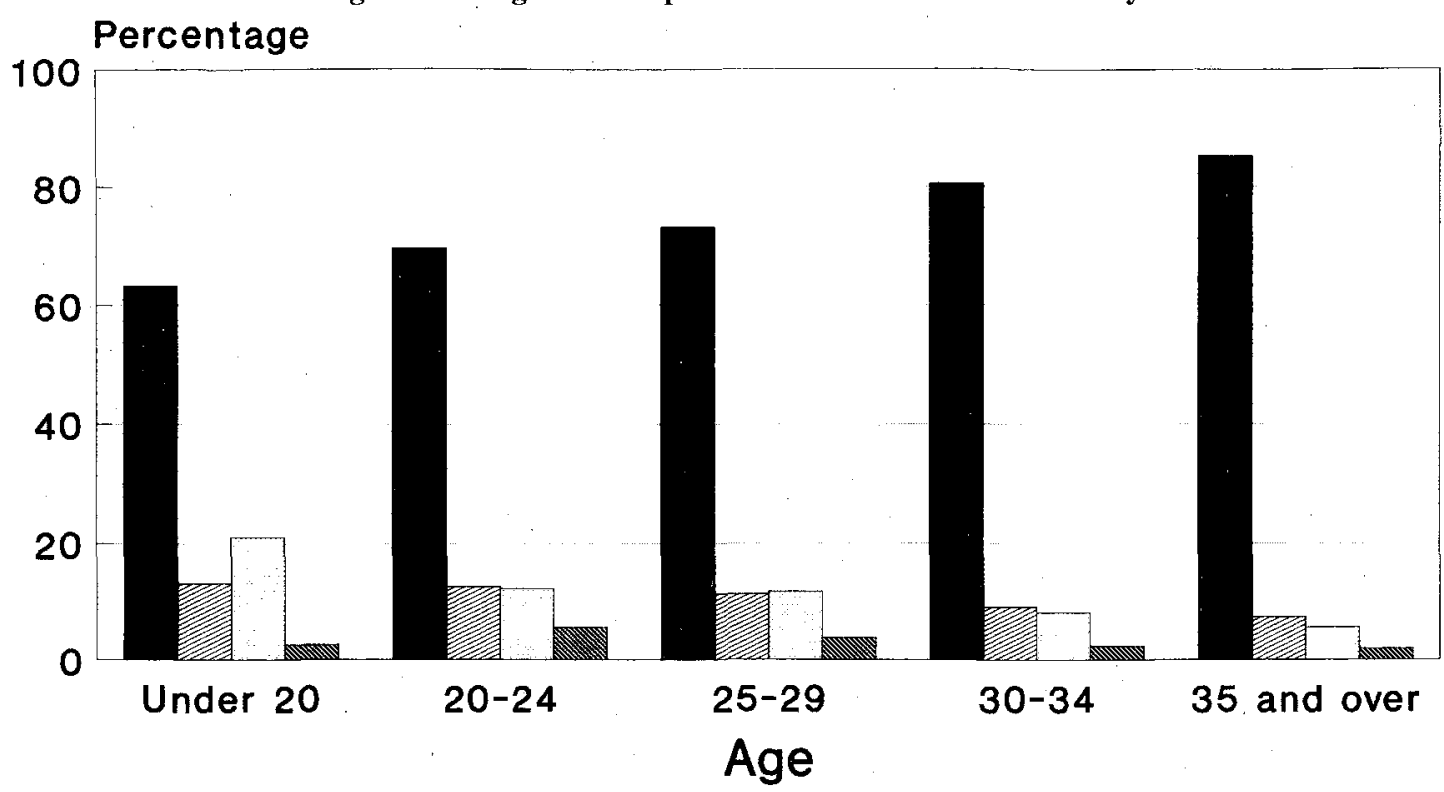

Non-smokers

$\square$ Moderate smokers

Light smokers

Heavy smokers

$\mathrm{N}=1002$

Fig 5. Maternal smoking by age in British Forces Germany 
study. Nevertheless if used with discretion these comparisons are a valuable starting point when assessing parenting habits in the military community.

The prevalence of prone sleeping position was extremely low at $1 \%$. Parents in British Forces Germany had clearly heeded the advice of the Department of Health which had been passed on by general practitioners and health visitors. This was an even better response than that demonstrated in a similar study in Cambridgeshire which found $4 \%$ of parents still placing their infants in the prone position to sleep (7).

Although ascertaining the prevalence of overheating was beyond the scope of this study it did show that the SSAFA initiative of issuing room thermometers to the parents of all new-born babies had resulted in their widespread use with $93 \%$ of families claiming to be using them. By comparison only $22 \%$ of parents in the Cambridgeshire study used a room thermometer (7). At the very least this suggests a high level of awareness of the problem of overheating in infancy throughout British Forces Germany.

Twenty nine percent of mothers in British Forces Germany had smoked during pregnancy which is no worse than the findings in most recent British civilian surveys $(13,14)$. When rates for smoking in pregnancy in British Forces Germany and in the North Western Region of England were compared using logistic regression analysis there was no significant difference after adjustment had been made for age $(\mathrm{p}=0.57)$. However parental smoking in the military community compared unfavourably with a recent study of mothers of new-born babies in Cambridgeshire (7). In the Cambridgeshire study $22 \%$ smoked antenatally (compared with $29 \%$ ) and there was another smoker in $26 \%$ of households (compared with 34\%).

Although failure to breastfeed is not accepted as a risk factor for cot death in this country (although it is in New Zealand) the prevalence of breastfeeding in British Forces Germany was investigated in this survey. Fifty one percent of mothers in the military community were breast feeding to some extent at the time of first health visitor contact which is exactly the same proportion of mothers that was found to be still breastfeeding after two weeks in a major survey of the civilian population of the United Kingdom (15). Since breastfeeding is definitely beneficial for other reasons it was reassuring to find that breastfeeding rates in British Forces Germany did at least compare satisfactorily with those for the civilian population of England and Wales.

The benefit of infants sharing the same room as their parents has not been established but the prevalence of this practice is nevertheless of interest. The proportion of families whose babies always slept in the same room as their parents in British Forces Germany was $86 \%$ and was therefore even higher than that found in the Cambridgeshire study (7).

The high prevalence of smoking in pregnancy and amongst the parents of new-born babies which was

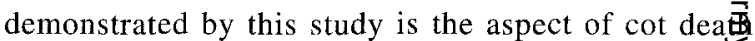
prevention which most merits attention and further heal promotion efforts need to be targeted at women smokes who are pregnant or are planning pregnancy and also their partners. This is in line with the Department Health's strategy for health in England which has as ome of its targets the requirement to increase the proportion of: women smokers who give up smoking at the start of thef pregnancy from a quarter to at least a third by the ye $2000(16)$.

Health promotion efforts aimed at reducing smoking are more likely to be effective if directed in accordane with the findings of various research studies. It has beeft found that pregnant women are more likely to give un smoking if they smoke less than twenty cigarettes per day have previously quit for more than one week, have a not smoking spouse (the husbands of one third of the smoking mothers in this study were non-smokers) and recognis that smokers' children are more likely to suffer from infections $(13,17)$. Unfortunately the prospect of givin birth to a small baby because of smoking does not seem $t p$ deter pregnant women from doing so and therefore tis increased risk of childhood infections and cot death need to be stressed as well. Research has also shown that health promotion efforts aimed at helping women to given smoking in preparation for pregnancy or during pregnancy need to be conducted with high intensit? order to be effective $(18,19)$.

Health promotion intervention programmes invarizolg require extra resources. The study showed considergh variation in maternal age, with corresponding smo rates, between the different garrisons in British Fo Germany and this has important resource implication health promotion is to be targeted where it is most needed. Health visitors in the garrisons where mothers a youngest and smoking rates highest will be least able tackle the problem of smoking in pregnancy withog increased support.

\section{Acknowledgements}

The authors thank all health visitors working $f$ 료 SSAFA in British Forces Germany without whose he $\vec{P}$ this study would not have been possible. Essenti information was provided by Medical Branci Headquarters United Kingdom Support Comman (Germany) and by the SSAFA Community Midwifer Service. Dr Abdalla from the Department of Medicat. Statistics at the London School of Hygiene and Tropice Medicine kindly gave statistical advice.

\section{References}

1. FinLAY F, RudD P. Current concepts of the aetiolog of SIDS. Br J Hosp Med 1993; 49: 727-732.

2. Golding J, Limerick S, Macfarlane A. Sudden Infant Death: Patterns, Puzzles and Problems Somerset, England: Open Books Publishing Ltd, 198.5

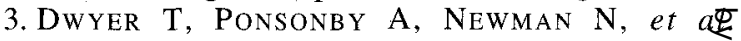
Prospective cohort study of prone sleeping and suddem 
infant death syndrome. Lancet 1991; 337: 1244-1247.

4. Fleming P, Gilbert J, Azaz Y. Interaction between bedding and sleeping position in the sudden infant death syndrome: a population-based case control study. Br Med J 1990; 301: 85-89.

5. Hagland B, CNattingius S. Cigarette smoking as a risk factor for sudden infant death: a population-based study. Am J Public Health 1990; 80: 29-32.

6. Wigfield R, Fleming P, Berry P, et al. Can the fall in Avon's sudden infant death rate be explained by changes in sleeping position? Br Med J 1992; 304: 282-3.

7. Hiley C, Morley C. Evaluation of government's campaign to reduce risk of cot death. Br Med J 1994; 309: $703-4$.

8. Gilbert R, Rudd P, Berry P, et al. Combined effect of infection and heavy wrapping in sudden infant death. Arch Dis Child 1992; 67: 171-177.

9. Department of Health. Report of the Chief Medical Officer's Expert Group on the sleeping position of infants and cot death. London: HMSO, 1993.

10. Davies D, Gantley M. Ethnicity and the aetiology of sudden infant death syndrome. Arch Dis Child 1994; 70: 349-353.

11. Mitchell E, Scragg R, Stewart A, et al. Results from the first year of the New Zealand cot death study. NZ Med J 1991; 104: 71-76.

\section{G.D.Golding Tailors Lrd.

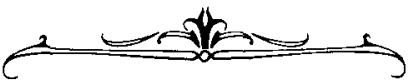

MILITARY AND CIVILIAN TAILORS

We are pleased to be Regimental Tailors by Appointment to The Royal Army Medical Corps

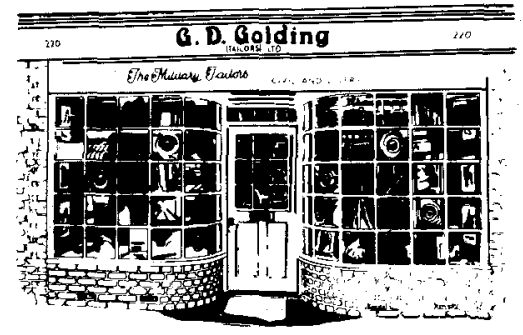

220 Hatfield Road, St. Albans Hertfordshire AL1 4LW

Telephone: St. Albans (01727) 841321 Facsimile: (01727) 831462
12. Office of Population Censuses and Surveys (OPCS Birth Statistics 1992. Series FM1 No.21.

13. Cnattingius S, Lindmark G, Meirik O. Wh continues to smoke while pregnant? I Epidemiof Community Health 1992; 436: 218-221.

14. Forrest D, Horsley S, Roberts E, et al. Factogs relating to smoking and pregnancy in the North

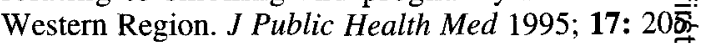
210.

15. White A, Freeth S, O'Brien M. Infant Feeding 1990. London: HMSO, 1992.

16. Department of Health. Smoke free for health. Ag Action plan to achieve the Health of the Nation targets on smoking, 1994.

17. OLSEN J. Predictors of smoking cessation $\overrightarrow{\mathrm{m}}$ pregnancy. Scand J Soc Med 1993; 21: 197-202.

18. KENDRICK J, ZAHNiSER S, MiLler N, et al. Integratiog smoking cessation into routine public prenatal cat: the Smoking Cessation in Pregnancy project. $A m$ 기 Public Health 1995; 85: 217-22.

19. Dolan-Mullen P, Ramirez G, Grof J. A met底 analysis of randomized trials of pre-natal smoking cessation interventions. Am J Obstet Gynecol 1994. 171: $1328-34$.

Did you serve in the Falklands?

If so, this may be of interest to you: 14 JUNE 1982, SURRENDER DOCUMENTS SIGNEB 14 JUNE 1997, 15 YEARS ON, A REUNION

To be held at

THE POLO FIELDS - HMS SULTAN

PLEASE RESPOND EARLY AS NUMBERS ARE CRITICAL FOR THE PLANNING OF THIS EVENT

When replying please state your name, rank, service number and in which ship or unit you served, plus a stamped addressed envelope to ensure you receive further information on this ever?

Volunteers are required to act as liaison officers for individua? ships and units. If you are interested, please mention this in your reply.

In the bottom left hand corner of the envelope, please put yous ship or units name.

Please reply to:

The Falklands Reunion

c/o The Post Office

HMS Sultan

Military Road

Gosport

Hampshire PO12 3BY 